\title{
Excessive adiposity is associated with an inflammation induced elevation in serum hepcidin, serum ferritin and increased risk of iron overload
}

\author{
Aoibhín Moore Heslin ${ }^{1}$, Aisling O’ Donnell ${ }^{1}$, Maria Buffini ${ }^{1}$, Anne Nugent ${ }^{1,2}$, Janette Walton ${ }^{3}$, \\ Albert Flynn ${ }^{3}$ and Breige McNulty \\ ${ }^{1}$ UCD Institute of Food and Health, University College Dublin, Dublin, Ireland, \\ ${ }^{2}$ Institute for Global Food Security, Queens University Belfast, Belfast, United Kingdom and \\ ${ }^{3}$ School of Food and Nutritional Sciences, University College Cork, Cork, Ireland
}

\section{Abstract}

Excess body fat is associated with the production of pro-inflammatory molecules from dysfunctional adipose tissue resulting in systemic inflammation. Inflammation stimulates expression of the iron regulatory hormone hepcidin, resulting in elevated serum ferritin and iron overload in metabolic tissues. Hepcidin driven iron maldistribution may be implicated in the development of metabolic diseases such as Type 2 diabetes and CVD. The aim of this study was to investigate the effect of body fat and the associated inflammation on markers of iron homeostasis.

Analyses were based on data from the cross-sectional National Adult Nutrition Survey (2008-2010) (www.iuna.net). Percentage body fat $(\mathrm{BF} \%)$ of participants $(\mathrm{n}=1211)$ was measured by a Tanita BC420MA device. Participants were classified as healthy, overweight or obese based on age and gender-specific $\mathrm{BF} \%$ ranges. Serum ferritin and serum hepcidin were measured using immunoturbidimetric immunoassays. ANCOVA with Bonferroni post hoc $(\mathrm{p}<0.05)$ was used to compare anthropometric parameters, biochemical markers of iron status and inflammation and nutrient intakes between $\mathrm{BF} \%$ groups. Predictors of serum hepcidin and serum ferritin were determined using linear regression analysis.

In the population $42 \%$ were classified as healthy, $33 \%$ as overfat and $25 \%$ as obese. Serum hepcidin was significantly elevated in obese participants $(8.42 \mathrm{ng} / \mathrm{ml} \pm 4.2)$ compared to their healthy counterparts $(6.49 \mathrm{ng} / \mathrm{ml} \pm 3.9)(\mathrm{p}<0.001)$. Significantly higher serum ferritin was observed in obese $(223 \mathrm{ng} / \mathrm{ml} \pm 170)$ and overfat males $(166 \mathrm{ng} / \mathrm{ml} \pm 120)$ compared to healthy males $(135 \mathrm{ng} / \mathrm{ml} \pm 91)(\mathrm{p}$ $<0.001)$. A significant percentage of overweight $(20 \%)$ and obese $(32 \%)$ participants were at severe risk of iron overload compared to healthy participants $(8 \%)(\mathrm{p}<0.001)$. No significant differences in dietary iron intakes were observed between $\mathrm{BF} \%$ groups. Linear regression analysis indicated that $\mathrm{BF} \%$ was a significant $(\mathrm{p}<0.001)$ predictor of hepcidin in males $(\beta=0.327)$ and females $(\beta=0.226)$. IL-6 $(\beta=0.317, \mathrm{p}<0.001)$ and TNF $\alpha(\beta=0.229, \mathrm{p}<0.001)$ were the strongest inflammatory predictors of hepcidin in females only. In males, leptin was a positive predictor $(\beta=0.159, p=0.003)$ of hepcidin, while adiponectin displayed a negative predictive relationship $(\beta=-0.145, \mathrm{p}=0.001)$

Our results indicate that excessive adiposity is associated with elevated serum ferritin and hepcidin independent of dietary intake. Cytokines are a potential driver of hepcidin in females, with adipose-derived hormones seeming to have the greater effect in males. These results may help to elucidate the relationship between obesity and dysregulated iron metabolism. Further research is required to investigate the metabolic effects of hepcidin-induced iron overload in those with excess body fat.

\section{Conflict of Interest}

There is no conflict of interest 